\title{
InspirAção: barreiras e facilitadores da comunicação segura sobre o suicídio
}

\author{
InspirAção: barriers and facilitators of safe communication about suicide \\ InspirAção: barreras y facilitadores de la comunicación segura sobre el suicídio
}

Recebido: 03/02/2021 | Revisado: 07/02/2021 | Aceito: 08/02/2021 | Publicado: 17/02/2021

Camila Corrêa Matias Pereira

ORCID: https://orcid.org/0000-0001-6910-4148 Universidade de São Paulo, Brasil

E-mail: milamatias@usp.br

Kelly Graziani Giacchero Vedana

ORCID: https://orcid.org/0000-0001-7363-2429

Universidade de São Paulo, Brasil

E-mail: kellygiacchero@eerp.usp.br

\begin{abstract}
Resumo
O suicídio é um grave problema de saúde pública mundial. A Comunicação Segura é importante recurso para a prevenção do suicídio por meio da conscientização, abordagem acolhedora, busca de ajuda, divulgação de conteúdos preventivos e redução de conteúdos ou interações que potencializem o risco de suicídio entre indivíduos vulneráveis. O objetivo deste estudo foi analisar barreiras e facilitadores da comunicação segura sobre o suicídio em produções discursivas sobre experiências e mensagens de apoio. Trata-se de um estudo qualitativo, realizado em ambiente virtual e submetido à Análise Temática. Dentre os "Facilitadores" foram identificados: "O incentivo para a busca de ajuda profissional", "A propensão a oferecer ajuda" e "A crença na possibilidade de superação". Dentre as "Barreiras" relacionadas à comunicação segura sobre o suicídio, foram construídas 3 categorias: "Recusa de Ajuda e a Dificuldade em ofertar ajuda", "Estigma e Culpabilização" e "Preocupação com o Despreparo". Entre nas "Possibilidades Ambivalentes", foram encontradas a "Religiosidade" e "Experiência pessoal e conselhos". A possibilidade da identificação de facilitadores e barreiras para a comunicação segura sobre o suicídio pode ser fundamental para a elaboração de estratégias de prevenção e promoção em saúde, potencializando os facilitadores e eliminando ou reduzindo as possíveis barreiras.
\end{abstract}

Palavras-chave: Suicídio; Comunicação; Pesquisa qualitativa.

\begin{abstract}
Suicide is a serious public health problem worldwide. Safe Communication is an important resource for preventing suicide through awareness, a welcoming approach, seeking help, disseminating preventive content and reducing content or interactions that increase the risk of suicide among vulnerable individuals. The aim of this study was to analyze barriers and facilitators of safe communication about suicide in discursive productions about experiences and messages of support. It is a qualitative study, carried out in a virtual environment and submitted to Thematic Analysis. Among the "Facilitators" were identified: "The incentive to seek professional help", "The propensity to offer help" and "The belief in the possibility of overcoming". Among the "Barriers" related to safe communication about suicide, three categories were built: "Refusal of Help and Difficulty in offering help", "Stigma and Guilt" and "Concern about Unpreparedness". Between "Ambivalent Possibilities", we found "Religiosity" and "Personal experience and advice". The possibility of identifying facilitators and barriers for safe communication about suicide can be fundamental for the development of prevention and health promotion strategies, empowering facilitators and eliminating or reducing possible barriers.
\end{abstract}

Keywords: Suicide; Communication; Qualitative research.

\section{Resumen}

El suicidio es un grave problema de salud pública en todo el mundo. La comunicación segura es un recurso importante para prevenir el suicidio a través de la concientización, un enfoque acogedor, la búsqueda de ayuda, la difusión de contenido preventivo y la reducción de contenido o interacciones que aumentan el riesgo de suicidio entre personas vulnerables. El objetivo de este estudio fue analizar barreras y facilitadores de la comunicación segura sobre el suicidio en producciones discursivas sobre experiencias y mensajes de apoyo. Se trata de un estudio cualitativo, realizado en un entorno virtual y sometido a Análisis Temática. Entre los "Facilitadores" se identificaron: "El incentivo para buscar ayuda profesional", "La propensión a ofrecer ayuda" y "La creencia en la posibilidad de superación". Entre las "Barreras" relacionadas con la comunicación segura sobre el suicidio, se construyeron tres categorías: "Rechazo de ayuda y Dificultad para ofrecer ayuda", "Estigma y culpa" y "Preocupación por la falta de preparación". Ingrese "Posibilidades ambivalentes", busque "Religiosidad" y "Experiencia y consejos personales". La posibilidad de 
identificar facilitadores y barreras para la comunicación segura sobre el suicidio puede ser fundamental para el desarrollo de estrategias de prevención y promoción de la salud, empoderando facilitadores y eliminando o reduciendo posibles barreras.

Palabras clave: Suicidio; Comunicación; Investigación cualitativa.

\section{Introdução}

O suicídio é um grave problema de saúde pública mundial, afetando todas as idades, gêneros e regiões do mundo, sendo cada morte uma perda muito grande (World Health Organization, 2019). Estima-se que a cada 40 segundos uma pessoa morra por suicídio, totalizando aproximadamente 800.000 pessoas todos os anos, (World Health Organization, 2019) tendo as tentativas de suicídio taxas ainda mais elevadas, podendo chegar a dez ou vinte vezes o número de mortes, sendo um importante fator de risco para o suicídio (World Health Organization, 2014). Nos últimos 45 anos, as taxas de suicídio aumentaram 60\% no mundo (World Health Organization, 2020), sendo a segunda principal causa geral de morte entre 15 a 29 anos (World Health Organization, 2014) e entre as terceiras principais causas de morte em 15-44 anos em ambos os sexos (World Health Organization, 2020).

A redução da mortalidade por suicídio é uma prioridade da Organização Mundial de Saúde (OMS) e um dos indicadores dos objetivos de Desenvolvimento Sustentável da Organização das Nações Unidas (ONU), de forma a garantir a que o suicídio não continue a custar vidas (World Health Organization, 2014). Considerando os múltiplos fatores envolvidos no comportamento suicida, diferentes setores da sociedade têm um papel fundamental na identificação de situações de risco, promoção de fatores de proteção, combate ao estigma e oferecimento de suporte (World Health Organization, 2014).

De acordo com recomendações da Organização Mundial da Saúde (OMS), as ações preventivas devem incorporar a orientação sobre o comportamento suicida para a sociedade em geral, a redução de estigma e o envolvimento da mídia para que essa evite a disseminação de conteúdo pró-suicídio, o “efeito contágio” e colabore com ações preventivas, (World Health Organization, 2014). Ademais, a OMS aponta que a comunidade em geral pode desempenhar um papel muito importante na prevenção do suicídio, podendo oferecer suporte social para indivíduos vulneráveis, proporcionar acompanhamento no cuidado da população, combate ao estigma e oferecimento de suporte (World Health Organization, 2014).

Estratégias com o objetivo de desencorajar o comportamento suicida, apoiar pessoas com desesperança, divulgar informações fidedignas e formas de procurar ajuda são consideradas importantes e necessárias para a prevenção do suicídio (Gomes, Baptista, Carneiro, \& Cardoso, 2014). Uma prevenção efetiva requer, além da conscientização da comunidade acerca do comportamento suicida, a capacidade de identificação de pessoas vulneráveis, encorajamento para a busca por apoio, bem como a redução de fatores de risco e promoção de fatores de proteção específicos identificados entre esses grupos (World Health Organization, 2014).

O conceito de Comunicação Segura é importante no desenvolvimento de campanhas de conscientização da comunidade e conteúdo relacionado à prevenção do suicídio para garantir que as mensagens públicas sobre suicídio não aumentem involuntariamente o risco de suicídio para indivíduos vulneráveis que recebem estas mensagens. A comunicação segura também é importante para treinar jovens e membros da comunidade para aplicar esses conceitos à comunidade a qual pertencem (Antonio, Chung-Do, Goebert, Bifulco, \& Alvarez, 2020). Dessa forma, o objetivo deste estudo foi analisar barreiras e facilitadores da comunicação segura sobre o suicídio em produções discursivas sobre experiências e mensagens de apoio.

\section{Metodologia}

\section{Desenho do estudo}

Trata-se de um estudo qualitativo realizado em ambiente virtual através do Google Forms no período de outubro de 2018 a fevereiro de 2019. O método qualitativo utiliza da interpretação por meio do pesquisador, através de dados descritivos, 
sendo importante o "significado" atribuído pelos participantes por trás da pergunta de pesquisa (Pereira, Shitsuka, Parreira, \& Shitsuka, 2018).

\section{População e critérios de seleção}

Participaram do estudo 338 indivíduos. Foram elegíveis usuários da internet que possuíam e-mail ou conta ativa no facebook no momento da coleta e fossem alfabetizados. Foram excluídos da pesquisa menores de 18 anos e pessoas que não responderam ao convite para o estudo após três tentativas de contato.

Foi realizada a amostragem por bola de neve, uma forma de amostra não probabilística que utiliza cadeias de referência para o estudo de grupos. A amostragem foi operacionalizada por meio do último item do roteiro para a coleta de dados no qual houve a solicitação de que os participantes do estudo indiquem o contato de, ao menos, uma pessoa para participar do estudo. Assim a amostragem foi gerada através de ligações de rede em cadeia, expandindo-se (Heckathorn, Douglas; Cameron, 2017). O Tipo de Amostragem "Bola de Neve", é útil para estudar determinados grupos de difíceis acessos através de "sementes" (informantes-chaves), para a localização de pessoas com o perfil necessário para a pesquisa, pedindo que as sementes indiquem novos contatos e assim sucessivamente, crescendo o quadro da amostragem até a saturação (Vinuto, 2014).

\section{Coleta de dados}

Foi escolhida como fonte de coleta de dados do presente estudo a ferramenta do Google "GOOGLE FORMS", que possui alguns recursos que tornam possível a coleta e organização de respostas e informações em pequena ou grande quantidade, de forma rápida, gratuita e online.

A coleta de dados foi realizada por meio de um questionário criado especificamente para esse estudo, com questões fechadas sobre sexo, idade, ocupação, se possuíam alguma crença religiosa ou espiritualidade e as perguntas abertas descritas a seguir: "você tem alguma história que gostaria de compartilhar sobre ter ajudado alguém que poderia estar em risco suicida?" e “o que você diria para ajudar alguém em risco de suicídio (mensagem de apoio)?”. Ao final do formulário, havia uma questão para que o entrevistado indicasse o contato de uma pessoa para ser convidada a participar do estudo.

\section{Análise e Tratamento dos Dados}

Os dados foram analisados através da Análise Temática, que caracteriza-se por ser um método qualitativo que permite identificar, analisar, organizar, descrever e reportar comunicações e padrões encontrados dentro de um conjunto de dados estudados. Consistiu nas seguintes fases: familiarização com os dados, construção de códigos iniciais, busca por temas, análise dos temas, definição e atribuição de nomes aos temas e produção do relatório (Nowell, Norris, White, \& Moules, 2017). Foi utilizada análise quantitativa descritiva para a análise dos dados obtidos sobre as características dos indivíduos e das mensagens destes indivíduos que responderam ao Google Forms.

\section{Aspectos éticos}

O estudo foi iniciado após autorização por Comitê de Ética em Pesquisa e seguiu as recomendações da Resolução $\mathrm{n}^{\circ}$ 466/2012 sobre pesquisa envolvendo seres humanos. Os participantes do estudo foram esclarecidos através do Termo de Consentimento Livre e Esclarecido (TCLE) quanto ao anonimato e sigilo das informações, os objetivos do estudo, e a liberdade para interromper a participação na pesquisa em caso de necessidade, sem que isso lhes acarrete dano pessoal. A participação foi voluntária e sem fins lucrativos. 


\section{Resultados}

Participaram do estudo 338 indivíduos, sendo que a maioria era do sexo feminino (67,9\%), com nível superior completo ou em andamento (68,2\%), adepta de crenças religiosas (86\%), com a idade entre 21 a 30 anos $(57,1 \%)$. Em relação à ocupação, a maior parte era estudante $(36,9 \%)$ ou trabalhava na área da saúde $(24,2 \%)$.

Para a comunicação segura relacionada ao suicídio, dentre os "Facilitadores", foram construídas 3 categorias: "O incentivo para a busca de ajuda profissional”, “A propensão a oferecer ajuda" e "A crença na possibilidade de superação”. Dentre as "Barreiras" relacionadas à comunicação segura sobre o suicídio, emergiram 3 categorias "Recusa de Ajuda e a Dificuldade em ofertar ajuda", "Estigma e Culpabilização" e "Preocupação com o Despreparo". Já nas "Possibilidades Ambivalentes", emergiram 2 categorias, sendo "Religiosidade" e "Experiência pessoal e conselhos".

\section{Facilitadores para a Comunicação Segura sobre o Comportamento Suicida}

\section{O incentivo para a busca de ajuda profissional}

Os participantes da pesquisa destacaram o quanto era importante a busca de ajuda profissional para pessoas que pudessem estar em risco suicida. Nesse sentido, foram destacados os serviços especializados em saúde mental. Essa temática foi transversal na pesquisa, estando muito presente nas questões investigadas neste estudo, ressaltando a importância do acompanhamento e encaminhamento ao serviço profissional.

"Meu namorado. Ele entrou em depressão, tinha síndrome do pânico, dizia se ver pulando a janela do apartamento, não desejava pular, mas se via pulando. Procuramos tratamento imediato e ele mantém o tratamento" (R12)

"Uma amiga se automutilava, sempre tentava ajuda-la, sem êxito. Com receio de ela tomar uma atitude drástica, a levei em um psicologo." (R149)

"em uma unidade de saúde, uma paciente dizia estar ouvindo vozes. Perguntei o que elas diziam e ela respondeu que a voz dizia que ia matá-la. Acionamos a equipe de enfermagem e ela foi encaminhada ao serviço especializado. Um tempo depois encontrei-a em outro serviço" (R203)

Os entrevistados também demonstraram o entendimento da complexidade e singularidade do comportamento suicida e a temática como uma condição que requer cuidados em saúde. Também foi mencionada a importância da Equipe Multiprofissional e da Intersetorialidade para o melhor acompanhamento continuado de pessoas com risco suicida.

"Minha vida é pautada pelo caos e aleatoriedades. Sou vivo e me mantenho assim por uma infinidade de acontecimentos aleatórios. Então, não sou capaz de gerar uma mensagem tão abrangente assim. Penso que cada pessoa possui uma história diferente. Deste modo, sintetizar seria um erro." (R194)

"um filho de uma amiga estava com sinais de iria tirar a própria vida, encorajei a mãe dele a buscar ajuda em núcleo de saúde mental, conseguindo uma consulta com um especialista e a orientando com processo de terapia. Ele melhorou muito e ela tbem procurou ajuda pra ela e o outro filho." (R74)

"Trabalho em uma academia e lá tento conversar com todos os alunos. Esse ano um aluno veio conversar comigo e falou que fazia tratamento psicológico e que a psicologa incentivou a pratica da atividade física. E com o depoimento dele, ele deixou bem claro que não cometeu suicídio porque o exercício físico liberava toda essa vontade e claro junto com o tratamento psicológico. Com isso procurei a psicóloga e conversei com ela, dando todo meu apoio principalmente para esses casos de pessoas que pretende suicídio. E propus uma parceria, todos os pacientes dela (sem 
condição financeira) com forte tendencia ao suicídio (principalmente) para me procurar que iria acompanhar a pessoa com exercício físico (gratuitamente), junto ao tratamento dela. Já tenho duas pessoas comigo.” (R37)

\section{A propensão a oferecer ajuda}

A propensão a oferecer ajuda, formando uma rede de apoio e suporte social, foram temas abrangentes que apareceram com destaque nas perguntas, sendo considerados fatores protetores importantes para o indivíduo em risco de forma a oferecer ajuda, apoio, incentivo, atenção e cuidado nos momentos de maior vulnerabilidade.

“Meu irmão tem depressão e já disse várias vezes que não tem motivos para viver, nós da família sempre estamos por perto tentando ajudá-lo." (R94)

"Meu pai está se tratando de depressão e no início ele teve algumas crises em que falava em suicídio. A minha atenção e a da minha família para com ele foram redobradas e com muita paciência, carinho e amor hoje ele está bem melhor, não menciona mais a ideia de tirar sua vida e segue aos poucos retomando a sua rotina." (R118)

“Meu amigo passou, e ainda passa, por momentos difíceis porem, por mais que ele diga que está bem, que esta conseguindo seguir a vida, a qualquer momento, ele pode ter uma recaída e, por isso, ter o apoio dos amigos, estar rodeado de pessoas confiáveis ajuda a pessoa. Não para ficar vigiando-a, mas para mostra-la que se precisar todas aquelas pessoas estarão do seu lado, que não precisa passar por tudo isso sozinho, que dividir a carga que o incomoda, faz com que veja um caminho para seguir e superar. E, a cada dia, fazer esse exercício de se olhar no espelho e dizer: "Eu, até agora, superei todos os meus piores dias. Posso superar mais um." (R226)

Foram ainda destacados a importância da iniciativa, proatividade e disponibilidade na oferta de ajuda, bem como a escuta empática, reforçando a importância do apoio, do acolhimento, do incentivo e do não julgamento.

"Pessoas com depressão ou ansiedade normalmente não conseguem imaginar o fim de uma crise quando estão nela. Cabe às pessoas ao redor compreender e aceitar o tempo de absorção da situação da pessoa.” (R166)

“Eu me importo, eu converso sem julgar, apoio, incentivo... se ela está feliz, eu estou. Se ela não está feliz, farei algo pra ela ficar. Amor ainda cura algo!” (R57)

“Ter estado disponível para ouvir em silêncio" (R285)

\section{A crença na possibilidade de superação}

Entre os facilitadores da comunicação segura para prevenção do suicídio estão a percepção das mudanças no ciclo vital, a aceitação de que existem os "altos e baixos" da vida, bem como a resiliência e a capacidade de transformação desituações adversas.

"Que a vida é mais que isso, e que sempre vale a pena independente das adversidades. E que, quando tudo estiver indo de mal a pior, a situação é passageira por mais dolorosa que seja." (A4)

"Que a vida é feita de altos e baixos e que para tudo conseguimos encontrar uma saída. Nem sempre o que desejamos, mas podemos confiar que será o melhor.”(A19) 
Foram ainda mencionados fatores que podem promover o bem-estar. A concentração no momento presente também mostrou-se um recurso para promoção da resiliência. A lembrança dos motivos pra viver foi considerada como um fator protetivo do comportamento suicida e a ressignificação de processos atrelados à dor.

"Para pararem e contarem até dez, concentrando na sua própria respiração, pensar em quem o ama e quem ele ama; confiar que aquilo vai passar" (A12)

"Eu diria para a pessoa pensar sobre um motivo para viver hoje, que seja alguém que ama, algo que ainda não fez, ou até mesmo só para esperar o dia de amanhã, convidando a mesma a viver um dia de cada vez, para que assim a vida possa provar a ela que vale a pena esperar, vale a pena superar, vale a pena provar a dádiva de viver." (A245)

"Tentaria auxiliar a pessoa para ressignificar as coisas que já lhe aconteceu. Para tentar enxergar algo positivo na história de sua vida." (R27)

\section{Barreiras para a Comunicação Segura sobre o Comportamento Suicida \\ Recusa de Ajuda e a Dificuldade em ofertar ajuda}

Uma das barreiras encontradas nas respostas foi a da recusa de ajuda, relatando as dificuldades de lidar com o indivíduo que precisa de ajuda, mas não aceita ser ajudado e como essa questão afeta também o círculo familiar através de conflitos, discordâncias e limitações que podem prejudicar o tratamento e o convívio social.

“Convivo com esse risco praticamente diariamente, meu irmão, bipolar, homossexual, que estava desempregado em algumas das vezes, já tentou suicídio, ameaçou várias outras vezes, quis matar meu pai e de certa forma mata cada membro da nossa família pouco a pouco. As tentativas para ajudá-lo são difíceis de se pôr em prática, ele reluta, não aceita, tratamento medicamentoso faz quando quer, da forma que quere com o especialista que julga amenizar a situação, mas novamente quando ele quer. Acompanhamento psicológico nenhum pra ele está bom e ele abandona todos e diz que "nenhum funciona" (R38)

"Identifiquei numa conversa casual com minha mãe que ela tinha princípios de ideação suicida. Me sinto de mãos atadas pois ela não aceita procurar tratamento, e isso é doloroso para ela e para aqueles que estão ao seu redor. Mas, como filha, busquei evitar conflitos e embates, e me tornar cada vez mais próxima com mensagens de carinho, de apoio, relembrando o quanto ela é importante para mim e o quanto sou grata pela mãe maravilhosa que tenho." (R259)

Dentro dessa temática também apareceram relatos de pessoas que tentaram ou que gostariam de ajudar uma pessoa em risco de suicídio, mas que também possuíam uma condição de saúde que necessita de cuidado, apoio e atenção. No depoimento de sobreviventes enlutados, o sentimento de culpa foi relatado por não poder estar devidamente "presente" no auxílio da pessoa em sofrimento, por também estar experienciando uma situação de vulnerabilidade emocional e não saber como apoiar terceiros naquela situação.

“Eu enfrentei um transtorno psicológico da minha filha Onde precisou ser internada e lá pude ver muita coisa. Não sei se já chegavam a este ponto mas procurei dar força pra muitas pessoas e com isso encontrar a minha força pois precisava tanto quanto eles." (R101)

"Sim, mas infelizmente, por também estar doente, não consegui identificar o pedido de socorro da pessoa, que em seus últimos encontros comigo, perguntou-me insistentemente se eu tinha "ideações suicidas". Naquele momento meus olhos 
não viam nada além do meu próprio umbigo, minha própria dor e, em menos de 36 horas, no nosso próximo encontro, esta pessoa não apareceu... Foi a quarta tentativa de suicídio dela, e a segunda dentro do local de trabalho...e definitiva." (R201)

"Não ajudei quando pude, pois não levei fé quando ouvi que ele já tinha pensado em se matar, achei que não faria, pois fez... e agora vou ter que conviver com o peso de não ter feito nada quando pude..." (R50)

\section{Estigma e Culpabilização}

O Estigma é um fator limitante, uma desaprovação social de indivíduos ou grupos com características diferentes da norma e uma importante barreira para a informação e a comunicação em saúde, muitas vezes com crenças limitantes.

"Suicídio é uma covardia com as pessoas que nos amam." (A177)

Além do estigma, uma das temáticas que apareceram como barreira em relação à comunicação segura do comportamento suicida foi o "Sentimento de irrelevância quanto ao problema", com soluções extremamente simplistas e reducionistas para um problema tão complexo como o comportamento suicida.

"Que nada e tão ruim que justifique interromper a vida" (R30)

"A vida é uma dádiva e nos foi dada por Deus. Se está com problemas, olhe ao seu redor e verá que tem gente com dificuldades maiores." (R46)

"A vida é complicada, mas tudo passa" (R102)

Um outro dificultador importante foi o da culpabilização do indivíduo em risco de suicídio ou em sofrimento mental, não considerando mais uma vez a complexidade do problema e apostando em soluções fáceis, de pouca profundidade e de completa responsabilização pela melhoria da condição em saúde mental.

"A sua felicidade depende exclusivamente de você." (R18)

“O suicídio meu amigo(a) não ira acabar com seu sofrimento, só ira trazer angustias para sua família e não irá resolver seus problemas portanto seja forte, persista pois sei que no fundo sua vontade de viver seja maior mostre quem você realmente é e siga em frente." (R101)

A vida é única e rara. Existem pessoas lutando para sobreviver. Não existe problema que não tenha solução. (RI20) "Com tantas pessoas lutando para ter um dia a mais de vida, seria egoísmo tirar a própria vida", por mais que seja doloroso o motivo pelo qual a fez pensar em tirar a própria vida, nada justifica essa ação. Há meios e pessoas que podem ajudar a passar por esse momento!" (R121)

\section{Preocupação com o Despreparo}

Muitos participantes indicaram a dificuldade em saber como agir em uma situação onde precisam ou precisariam se comunicar com alguém em risco de suicídio e apresentaram preocupação com este despreparo. 
“Conheço alguém que tentou o suicido, mas não me sinto qualificado para falar do assunto com a pessoa." (R93)

"Em minha prática clínica tive experiência com três pacientes que tentaram suicídio. Lidar com a situação é como estar numa corda bamba." (R272)

“Sinceramente não sei ao certo.” (R274)

Ao mesmo tempo, entrevistados demonstraram ter contato com o assunto em alguns contextos delimitados, reforçando a necessidade de uma maior educação em saúde sobre a temática.

“Ajudei pacientes com pensamento suicida apenas durante os estágios de psiquiatria durante minha graduação” (R8)

"Na matéria de CIS I, realizei visitas domiciliares onde um dos integrantes da família demonstrou por algum momento o risco de cometer suicídio" (R10)

\section{Possibilidades Ambivalentes}

\section{Religiosidade}

Essa categoria foi um importante achado deste estudo, reforçando que todos os aspectos (físicos, biológicos e psicossociais) precisam ser considerados para uma comunicação segura sobre a temática de forma efetiva, considerando diferentes contextos e realidades em sua singularidade. Nesta categoria foi possível perceber algumas atitudes possivelmente menos proativas e mais expectantes, bem como, a fundamentação do apoio em crenças e recursos que podem não ser bem aceitos ou efetivos, a depender de cada indivíduo.

"Sim, devido minha religião católica sou pregadora do evangelho e ministro palavras de apoio que em muitos casos através do agir de Deus foram auxílio para pessoas com pensamentos suicida desestimulando-as a realizar o ato. Além disso minha mãe já cometeu o suicideo na minha frente, ficando por minha conta socorre-lá e salvar sua vida.” (R36)

“Que o suicídio pode até te aliviar dessa dor terrestre, mas seu espirito ainda vai continuar sofrendo. E por mais que você ache que é o fim do mundo e que você não aguenta mais esse fardo, tente mudar o seu redor e procure ajuda. Tudo tem como ser diferente, mas a gente tem que querer e lutar por isso, se ajudar também." (R37)

“Apenas rezaria por ela, mas diria que há um Deus que é maior que nossos problemas e que Ele jamais nos dá uma cruz maior do que aquela que possamos carregar. Ele escolhe os seus melhores soldados.” (R111)

"Falaria sobre a biblia” (R332)

\section{Experiência pessoal e conselhos}

O uso de experiências prévias e conselhos, foi utilizado na imposição de perspectivas já vivenciadas, no oferecimento de estratégias de ajuda e também como possibilidades de provocar a esperança em situações consideradas difíceis. Essa ação de aconselhamento vem a partir do entendimento de uma experiência prévia como uma possível forma de resolução de problemas, podendo desconsiderar diferentes contextos e realidades.

"Por já ter passado por uma depressão também, uso muito o meu caso como exemplo e tento repassar o que eu fiz para superá-la” (R17) 
"Sim. Em 2012 tive um CA de ovário. Nessa mesma época um cunhado só falava em suicidar-se. Quando ele me viu sem cabelos ficou assustado. Foi quando disse que eu estava lutando para viver,enquanto muitos queriam morrer. E que eu precisava ter muita fé para vencer a doença." (R39)

"Um amigo meu estava depressivo e eu contei minha história relacionada a depressao e ajudei ele a mudar de ideia sobre suicidio mostrando q não valia a pena e demonstrando a importância dele na minha vida” (R136)

“A pessoa foi deixado pelo namorado que já estava com outra mulher. Meu argumento foi: ele já está bem com uma outra pessoa, sua morte não vai o ferir ou magoar, mas se você se " repaginar", arrumar o cabelo, comprar roupas novas, se cuidar como nunca antes, além de atrair novos pretendentes, vai se sentir bem e é possível que ele percebe que "mulher" ele largou!" (R224)

“Apesar da dor que você está sentindo, não faça nada. Eu já passei por isso e sei que arrependi. A vida vale mais, ficar perto de pessoas vale mais, ter amigos, sair, curtir. A sua família e amigos te amam." (R54)

\section{Discussão}

A comunicação sobre o comportamento suicida ainda é um tópico complexo, que pode ter diferentes interpretações de acordo com o público alvo, sendo importante garantir que a comunicação ocorra de forma a não aumentar o risco do suicídio entre vulneráveis (Antonio et al., 2020; Ftanou et al., 2018). Entender como a busca de ajuda ocorre, pode ter diferentes implicações no desenvolvimento de estratégias efetivas para a prevenção do suicídio (Mok et al., 2020). Muitas pesquisas tem como foco os fatores de risco para o comportamento suicida, mas tão importante quanto são os fatores protetivos do comportamento suicida para as estratégias de prevenção (Sher, 2019).

No presente estudo, foram destacados três tipos de facilitadores sobre a comunicação segura sobre o comportamento suicida relacionados à ajuda profissional, a propensão a oferecer ajuda e a possibilidade de superação. Para melhorar e incentivar a busca de ajuda, é necessário entender os fatores associados com o comportamento da busca de ajuda, como também os facilitadores (literacia em saúde mental) e as barreiras (ideação suicida severa, estigma, crenças limitantes) (Hom, Melanie; Stanley, Ian; Joiner, 2015). A literacia em saúde mental e o estigma tem associação com a busca de ajuda emocional ou para o tratamento de transtornos mentais, sendo o aumento do conhecimento em saúde mental, experiências positivas com serviços de saúde e a redução do estigma como fatores importantes para uma maior busca de ajuda profissional e atitudes positivas entre indivíduos vulneráveis (Ma, Batterham, Calear, \& Han, 2019; Mok et al., 2020; Velasco et al., 2020).

As abordagens para melhorar a busca de ajuda em saúde mental por jovens, devem considerar o papel da Internet e dos recursos online como um importante complemento da procura de ajuda offline (Pretorius, Claudette, Chambers, Derek, Coyle, 2019). Ao mesmo tempo, profissionais da saúde que trabalham com jovens precisam ser informados sobre o plano de gestão de crises para a melhor compreensão de uma situação de risco de suicídio (Akca, Selen, O., Yuncu, O. Aydin, 2018).

Dentre os facilitadores, a propensão em oferecer ajuda está diretamente ligada à rede de apoio e formação de um sistema de suporte. Como facilitador, o apoio social e informal da família e amigos também desempenhou um papel importante na procura de ajuda profissional (Jin, Han, Batterham, Philip, Calear, Alison, Randall, 2018). O papel do suporte social, da família e o apoio da amizade estão associados à um risco reduzido do comportamento suicida (Nguyen, Ann, Taylor, Robert, Mitchell, 2018). Ainda de acordo com os facilitadores, se encontra a resiliência, capacidade de superação de adversidades de forma adaptativa, sendo um importante protetor contra o comportamento suicida e a incidência de transtornos relacionados ao estresse (Sher, 2019). As estratégias de prevenção do suicídio devem ter como objetivo o desenvolvimento de habilidades psicológicas, reduzindo os fatores de risco e promovendo os fatores de proteção como a resiliência (Rossetti et al., 2017). 
Dentre as "Barreiras", relacionadas à comunicação segura sobre o suicídio, a recusa de ajuda e o estigma foram duas das categorias presentes. O estigma e as crenças negativas sobre a saúde mental são importantes barreiras para os comportamentos de busca de ajuda (Velasco et al., 2020). É importante que os profissionais de saúde compreendam os efeitos do estigma no comportamento suicida para o fornecimento de apoio eficaz. Os sobreviventes de uma tentativa de suicídio podem se sentir envergonhados, culpados e julgados, resultando em desconforto e constrangimento, o que contribui para o sigilo, a não busca de ajuda, a evitação da temática, bem como sofrimento psicológico, depressão, autolesão e o suicídio (Evans, Amy, Abrahamson, 2020).

O estigma pode causar isolamento social, desmoralização, sentimento de desesperança e pode ser uma barreira na busca de ajuda profissional (Kučukalić, Sabina, Kučukalić, 2017). Revisão de Literatura realizada sobre os fatores que influenciam a busca de ajuda profissional em indivíduos com o comportamento suicida identificou potenciais barreiras na autossuficiência, falta de percepção da necessidade de tratamento, estigma em relação ao suicídio e os problemas de saúde mental; ao mesmo tempo, a presença de comportamento suicida e problemas de saúde mental diminuem a intenção de busca de ajuda (Jin, Han, Batterham, Philip, Calear, Alison, Randall, 2018). Este estudo encontrou o despreparo com as informações como um dos dificultadores da comunicação segura sobre o suicídio, sendo que, existe um déficit na formação para lidar com a temática, o que pode contribuir para um desconforto emocional dos profissionais por se sentirem despreparados, contribuindo com a limitação das possibilidades de atendimento ao comportamento suicida (Oliveira, Collares, Oliveira, Cristina, \& Dias, 2016). O comportamento suicida é complexo, multifatorial, compreende vários aspectos e a discussão sobre a temática alimenta o debate para a prevenção, tratamento, identificação do risco e intervenções (Gomes, Eliene Rocha, Iglesias, Alexandra, Constantinidis, 2017).

Dentre os dificultadores encontrados neste estudo, a primeira categoria abrange a recusa de ajuda e também a dificuldade em ofertar ajuda, reforçando uma dificuldade comum e geral dos indivíduos ao lidar com a temática. A falta de compreensão pela temática do suicídio reflete diretamente nas atitudes frente aos indivíduos com comportamento suicida, prejudicando a prevenção, afetando também a qualidade dos atendimentos (no caso de profissionais da saúde), dificultando o tratamento voltado à proteção da vida (Silva, Ferreira, Vasconcelos, \& Dutra, 2017). O cuidado em saúde precisa legitimar o sofrimento humano e a singularidade, convocando a intervenção de diversos profissionais com tomadas de decisões que correspondam à complexidade do tema (Gomes, Eliene Rocha, Iglesias, Alexandra, Constantinidis, 2017).

Dentre as possibilidades ambivalentes, uma categoria muito presente foi a da Religiosidade. O suicídio, como um fenômeno social deve considerar fatores sociais e a religião é um deles. Émile Durkheim relata um número mais elevado de suicídios no protestantismo quando comparado à religião católica por ser uma religião menos integrada e discorre sobre as características sociais da religião, com práticas comuns a todos os fiéis e com crenças obrigatórias, não por respeito ao indivíduo em sua singularidade, mas por estar em uma sociedade (Durkheim, 1982; Nunes, 1998)

A relação entre a Religião e o comportamento suicida é complexa pois ao mesmo tempo que pode apresentar fatores protetivos, pode apresentar fatores de risco. Cada religião pode apresentar diferentes estratégias de coping e pode também ser uma rede de apoio entre indivíduos vulneráveis (Edward \& Dana, 2018). A religiosidade, questões relacionadas à fé e espiritualidade podem ser úteis em situações de crise (Norko, MichaelFreeman, David, Phillips, James, Hunter, William, Lewis, Richard, Viswanathan, 2017)

Para adolescentes LGBTQI+, ser mais religioso e ter pais religiosos são fatores associados à um número maior de tentativas de suicídio quando comparados aos adolescentes que se relacionam com o sexo oposto, podendo contribuir para o estigma, conflitos relacionados à identidade sexual, sentimento de culpa, vergonha, rejeição, discriminação, preconceito e o risco para o comportamento suicida (Shearer, Annie, Russon, Jody, Herres, Joanna, Wong, Amanda, Jacobs, Carrie, Diamond, Gary, Diamond, 2017). 
A segunda categoria das possibilidades ambivalentes foi o "Aconselhamento/Experiência Prévia". Temas referentes ao comportamento suicida e o sofrimento mental ainda são tabus na nossa sociedade e por se tratarem de eventos multifatoriais ou multidimensionais, diversos aspectos devem ser considerados, como: desesperança, impulsividade, agressividade, pertencimento social, dificuldade de comunicação, percepção do corpo, orientação sexual, religião e religiosidade, consumo de álcool, transtornos mentais, sobreviventes, além das variáveis demográficas e socioeconômicas (Braga L de L, 2013; Gedeon, Mirianh, \& Paulo, 2017). Com tantas variáveis a serem consideradas, é complexo o aconselhamento/experiência prévia para situações de vulnerabilidade uma vez que o sujeito se coloca a partir da realidade que conhece, sendo improvável vivenciar e compreender todas as realidades possíveis e o sofrimento humano em sua singularidade.

\section{Conclusão}

Este estudo evidenciou a necessidade de sensibilização, conscientização e educação em saúde relacionadas ao comportamento suicida. Entre os facilitadores encontrados para a comunicação segura sobre o suicídio estiveram o incentivo para a busca de ajuda profissional, a propensão a oferecer ajuda e a crença na possibilidade de superação.

Em contrapartida, as barreiras identificadas para a comunicação segura sobre o suicídio foram relacionadas ao estigma, culpabilização, recusa de ajuda, dificuldade em ofertar ajuda e a preocupação com o despreparo ao lidar com a temática. Dentre as possibilidades ambivalentes, surgiram questões relacionadas à religiosidade e também à experiência pessoal e conselhos, podendo atuar como um fator de risco e também de proteção. A possibilidade da identificação de facilitadores e barreiras para a comunicação segura sobre o suicídio pode ser fundamental para a elaboração de estratégias de prevenção e promoção em saúde, potencializando os facilitadores e eliminando ou reduzindo as possíveis barreiras.

Como um potencial para pesquisas futuras, sugerimos a psicoeducação como um importante vetor para o aumento da literacia em saúde mental. Acreditamos que a produção de materiais científicos sobre a temática e iniciativas para a potencialização dos facilitadores citados neste estudo podem ser importantes estratégias para a promoção da saúde mental e a prevenção do suicídio.

\section{Agradecimentos}

O presente trabalho foi realizado com apoio da Fundação de Amparo à Pesquisa do Estado de São Paulo (FAPESP), processo $n^{\circ}$ 2017/24024-7. O presente trabalho foi realizado com apoio da Coordenação de Aperfeiçoamento de Pessoal de Nível Superior - Brasil (CAPES) - Código de Financiamento 001.

Este artigo é derivado de uma Tese de Doutorado intitulada "A comunicação nos ambientes virtuais e o comportamento suicida".

\section{Referências}

Akca, Selen, O., Yuncu, O. Aydin, Z. (2018). Mental status and suicide probability of young people : A cross-sectional study. Revista Da Associação Médica Brasileira, 64(1), 32-40.

Antonio, M. C. K., Chung-Do, J. J., Goebert, D. A., Bifulco, K., \& Alvarez, A. R. G. (2020). A Qualitative Evaluation of the Impacts of a Strength-based and Youth-driven Approach to Suicide Prevention in Rural and Minority Communities in Hawai'i. Hawai'i Journal of Health \& Social Welfare, 79(5), 96-100.

Braga L de L, D. D. D. (2013). Suicídio na adolescência: fatores de risco, depressão e gênero. Contextos Clínicos.

Durkheim, E. (1982). O Suicídio - Um Estudo Sociológico.

Edward, R., \& Dana, G. (2018). Religion and Suicide : New Findings. Journal of Religion and Health, 57(6), 2478-2499. https://doi.org/10.1007/s10943-018$0629-8$

Evans, A., Abrahamson, K. (2020). The Influence of Stigma on Suicide Bereavement: A Systematic Review. Journal of Psychosocial Nursing and Mental Health Services, 58(4). 
Ftanou, M., Skehan, J., Krysinska, K., Bryant, M., Spittal, M. J., \& Pirkis, J. (2018). Crafting safe and effective suicide prevention media messages: Outcomes from a workshop in Australia. International Journal of Mental Health Systems, 12(1), 1-8. https://doi.org/10.1186/s13033-018-0203-5

Gedeon, H., Mirianh, P., \& Paulo, C. De. (2017). Fatores associados à presença de ideação suicida entre universitários 1. Rev. Latino-Am. Enfermagem. https://doi.org/10.1590/1518-8345.1592.2878

Gomes, E. R., Iglesias, A., \& Constantinidis, T. (2017). Revisão Integrativa de Produçõ es Cient íficas da Psicologia Sobre Comportamento Suicida Integrative Literature Review of Scientific Productions of Psychology on Suicidal. Revista Psicologia e Saúde, 11(27), 35-53.

Gomes, J. O., Baptista, M. N., Carneiro, A. M., \& Cardoso, H. F. (2014). Suicídio e internet: análise de resultados em ferramentas de busca. Psicologia \& Sociedade, 26(1), 63-73. https://doi.org/http://dx.doi.org/10.1590/S0102-71822014000100008

Heckathorn, D.; \& Cameron, C. (2017). Network Sampling: From Snowball and Multiplicity to Respondent-Driven Sampling. Annual Review of Sociology, 43, $101-119$.

Hom, M.; Stanley, I.; \& Joiner, T. (2015). Evaluating factors and interventions that influence help-seeking and mental health service utilization among suicidal individuals: A review of the literature. Clinical Psychology Review, 40, 28-39.

Jin, H., Batterham, P., Calear, A., \& Randall, R. (2018). Factors influencing professional help-seeking for suicidality: A systematic review. Crisis: The Journal of Crisis Intervention and Suicide Prevention, 39(3), 175-196.

Kučukalić, Sabina, Kučukalić, A. (2017). Stigma and Suicide. Psychiatr Danub, 29(5).

Ma, J. S., Batterham, P. J., Calear, A. L., \& Han, J. (2019). Suicide Risk across Latent Class Subgroups: A Test of the Generalizability of the Interpersonal Psychological Theory of Suicide. Suicide \& Life-Threatening Behavior, 49(1), 137-154. https://doi.org/10.1111/sltb.12426

Mok, K., Chen, N., Torok, M., Mcgillivray, L., Zbukvic, I., Shand, F., Shand, F. (2020). Factors associated with help-seeking for emotional or mental health problems in community members at risk of suicide. Advances in Mental Health, O(0), 1-11. https://doi.org/10.1080/18387357.2020.1770109

Nguyen, A., Taylor, R., \& Mitchell, U. (2018). Extended family and friendship support and suicidality among African Americans. Social Psychiatry and Psychiatric Epidemiology, 52(3), 1-17. https://doi.org/10.1007/s00127-016-1309-1.Extended

Norko, M. F, David, P., James, H., William, L., \& Richard, V. R. (2017). Can Religion Protect Against Suicide? The Journal of Nervous and Mental Disease, 205(1).

Nowell, L. S., Norris, J. M., White, D. E., \& Moules, N. J. (2017). Thematic Analysis: Striving to Meet the Trustworthiness Criteria. International Journal of Qualitative Methods, 16(1), 1-13. https://doi.org/10.1177/1609406917733847

Nunes, E. D. (1998). O Suicídio - reavaliando um clássico da literatura sociológica do século XIX Durkheim ’s Suicide : reassessment of a classic from 19thcentury sociological literature. Cadernos de Saude Publica, 14(1), 7-18.

Oliveira, C. T. De, Collares, L. A., Oliveira, M. H., Cristina, A., \& Dias, G. (2016). Percepções De Uma Equipe De Saúde Mental Sobre O. Gerais: Revista Interinstitucional de Psicologia, 9(1), 78-89.

Pereira, A. S., Shitsuka, D. M., Parreira, F. J., \& Shitsuka, R. (2018). Método Qualitativo, Quantitativo ou Quali-Quanti. In Metodologia da Pesquisa Científica. https://repositorio.ufsm.br/bitstream/handle/1/15824/Lic_Computacao_Metodologia-Pesquisa-Cientifica.pdf?sequence=1

Pretorius, Claudette, Chambers, Derek, Coyle, D. (2019). Young People's Online Help-Seeking and Mental Health Difficulties: Systematic Narrative Review. Journal of Medical Internet Research, 21(11).

Rossetti, M. C., Tosone, A., Stratta, P., Collazzoni, A., Santarelli, V., Guadagni, E., ... Rossi, A. (2017). Different roles of resilience in depressive patients with history of suicide attempt and no history of suicide attempt. Brazilian Journal of Psychiatry, 39(3), 216-219. https://doi.org/10.1590/1516-4446-2016-2045

Shearer, A., Russon, J., Herres, J., Wong, A., Jacobs, C., Diamond, G., \& Diamond, G. (2017). Religion, Sexual Orientation, and Suicide Attempts Among a Sample of Suicidal Adolescents. Suicide \& Life-Threatening Behavior, 48(4).

Sher, L. (2019). Resilience as a focus of suicide research and prevention. Acta Psychiatrica Scandinavica, 140(2).

Silva, E. A. O., Ferreira, W. F. S., Vasconcelos, C. R., Dutra, D. A. (2017). Atitudes Dos Profissionais Da Suicídio Na Emergência Hospitalar Nursing Of Attitudes Against The Risk Of Suicide In The Emergency. Revista Saúde e Desenvolvimento|, (September).

Velasco, A. A., Silva, I., Cruz, S., Billings, J., Jimenez, M., \& Rowe, S. (2020). What are the barriers , facilitators and interventions targeting help-seeking behaviours for common mental health problems in adolescents? A systematic review.

Vinuto, J. (2014). A Amostragem Em Bola De Neve Na Pesquisa Qualitativa: Um Debate Em Aberto. Temáticas, 22(44), 203-220.

World Health Organization. (2014). Preventing suicide. CMAJ : Canadian Medical Association Journal = Journal de l'Association Medicale Canadienne, 143(7), 609-610. https://doi.org/ISBN: 9789241564779

World Health Organization. (2019). Suicide in the world: Global Health Estimates. World Health Organization,Geneva, 32.

World Health Organization. (2020). SUPRE Prevention of suicidal behaviours: a task for all. https://www.who.int/mental_health/prevention /suicide/information/en/ 